\title{
Granulomatous Reaction to Dermal Injection of Growth Factors from Umbilical Cord Blood-Derived Mesenchymal Stem Cells: A Case Report
}

\author{
Hee Joo Yang (D) \\ Hyoungmin $\mathrm{Na}$ \\ Woo Jin Lee \\ Sung Eun Chang \\ Mi Woo Lee \\ Chong Hyun Won
}

Department of Dermatology, University of Ulsan College of Medicine, Asan

Medical Center, Seoul, Republic of Korea

Correspondence: Chong Hyun Won Department of Dermatology, University of Ulsan College of Medicine, Asan Medical Center, 88 Olympic-ro 43 gil, Songpa-gu, Seoul, 05505, Republic of Korea

Tel +82-2-3010-3460

Fax +82-2-486-7831

Email drwon@amc.seoul.kr

\begin{abstract}
Use of stem cells to treat various diseases in dermatology has been of interest. Conditioned media with the growth factors secreted from stem cells has been used as a topical agent. We report a case of foreign body granulomas that appeared days after dermal injection of the conditioned media mimicking scars at all injection sites.
\end{abstract}

Keywords: granuloma, growth factor, mesenchymal stem cells, rejuvenation

\section{Introduction}

Use of stem cells in dermatology to treat various diseases and injuries including lipodystrophies, burns, connective tissue diseases, and aging has been in the limelight for several years. While some approaches focus on directly transplanting stem cells to repair tissue damage, others concentrate on using molecules secreted by stem cells to facilitate tissue repair. Conditioned media containing growth factors secreted by stem cells have shown effects in wound healing, skin rejuvenation, and hair loss. ${ }^{1}$ Paracrine effects of cytokines and growth factors including epidermal growth factor, fibroblast growth factor 2, fractalkine, granulocyte macrophage colony stimulating factor, interleukin 6, platelet-derived growth factor-AA, and vascular endothelial growth factor, secreted by stem cells may be responsible factors for skin rejuvenation. ${ }^{2}$ Along with skin's intrinsic age-related decline of restorative properties, extrinsic factors, such as ultraviolet light, induce skin aging through elastosis and increase of reactive oxygen species. ${ }^{3}$ Diverse skin rejuvenation treatments include topical products including topical retinoids, less invasive methods such as chemical peels, and more invasive treatments like dermal fillers. Conditioned medium proved its efficacy in skin rejuvenation when applied as a topical agent. Human stem cell conditioned medium combined with microneedling showed clinical improvement in pigmentation, erythema, and wrinkles in a randomized, controlled, blinded split-face study of 25 human subjects. ${ }^{4}$ Though dermal injection of conditioned media had not been reported in literature, injection of growth factors through platelet-rich plasma matrix have been studied. The injection stimulated dermal collagen formation and angiogenesis. ${ }^{5}$ Conditioned media have been produced as pharmaceuticals and proved its efficacy in augmenting regenerative effects of cosmetic laser therapy. ${ }^{6-8}$ Herein, we report a case of multiple foreign body granulomatous reactions at injection sites of conditioned medium obtained from human umbilical cord blood-derived stem cells. 


\section{Case Report}

A 54-year-old male presented with multiple relatively well-demarcated yellowish papuloplaques distributed in a grid pattern on the anterior of his neck (Figure 1). The patient had received a local injection of medium containing 89 active ingredients including growth factors obtained from human umbilical cord blood-derived stem cells to reduce neck wrinkles at a private clinic 7 months ago. The lesions appeared 3-4 days after the injection. A $4 \mathrm{~mm}$ punch biopsy of a papule was obtained at the first visit, 7 months after the lesions appeared. Histopathologic examination revealed a well-demarcated collection of macrophages around foreign materials. Multi-nucleated giant cells were detected at higher magnification (Figure 2). Alcian blue staining was negative and Periodic acidSchiff (PAS) staining did not reveal any fungal spores or hyphae (Figure 3). The patient had been a hepatitis $\mathrm{B}$ carrier and taken antiviral agents such as tenofovir for 30 years. The patient was diagnosed with hepatocellular carcinoma 6 months after the injection, but was otherwise healthy.

\section{Discussion}

Mesenchymal stem cells are multipotent cells that can be isolated from various sources such as bone marrow, adipose tissue, and umbilical cord blood, and are not associated with ethical concerns in contrast with their counterparts. Consequently, these cells have been used in various studies. A previous report showed that the RNA level of the rejuvenation factor Growth Differentiation Factor 11 is higher in mesenchymal cells derived from umbilical cord blood than in those derived from bone marrow and adipose tissue in vitro. ${ }^{9}$ In vivo topical application of conditioned media of umbilical cord bloodderived mesenchymal stem cells elicits anti-wrinkle and collagen-stimulating effects in humans. ${ }^{9}$

Growth factors and cytokines are hydrophilic molecules with molecular weights of more than 15,000 Daltons and consequently their penetration of the epidermis is a concern. ${ }^{10}$ Intradermal injection of growth factors rejuvenates skin and improves skin texture, thickness, and viscoelasticity. ${ }^{11}$ Although local injection of growth factors directly affects the dermis, other methods of
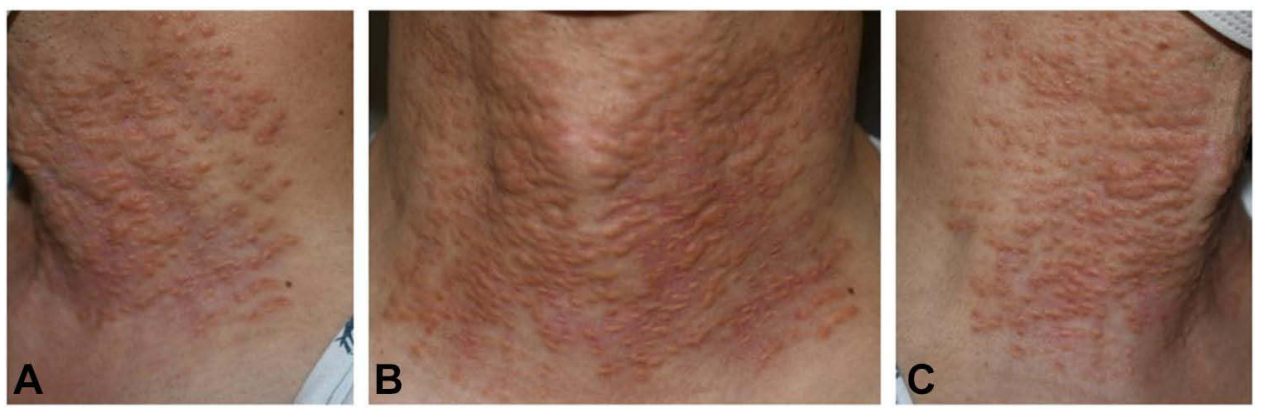

Figure I Clinical characteristics of the patient. Granulomas presented in the patient as multiple yellowish papuloplaques distributed in a grid pattern on the anterior of the neck were found at all injection sites. (A left view, B front view, C right view).
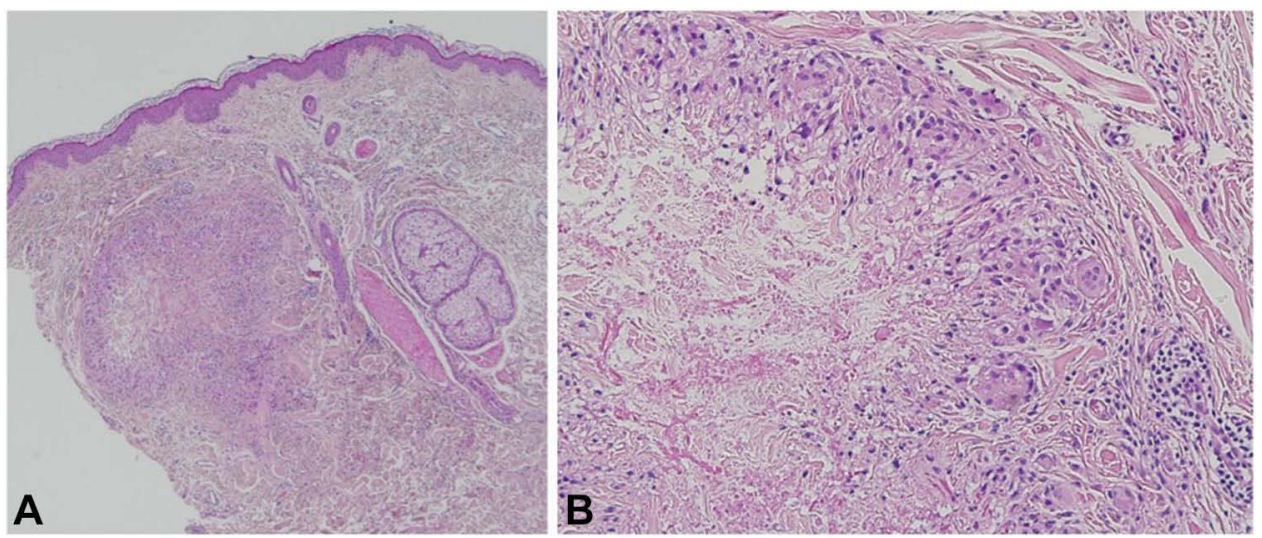

Figure 2 Histopathological characteristics of the patient. Dermal granuloma was found on histological examination of lesional skin with a well-demarcating feature. Macrophages and multi-nucleated giant cells were found along the periphery of the granuloma. (A hematoxylin-eosin, $\times 40$, B hematoxylin-eosin, $\times 200$ ). 


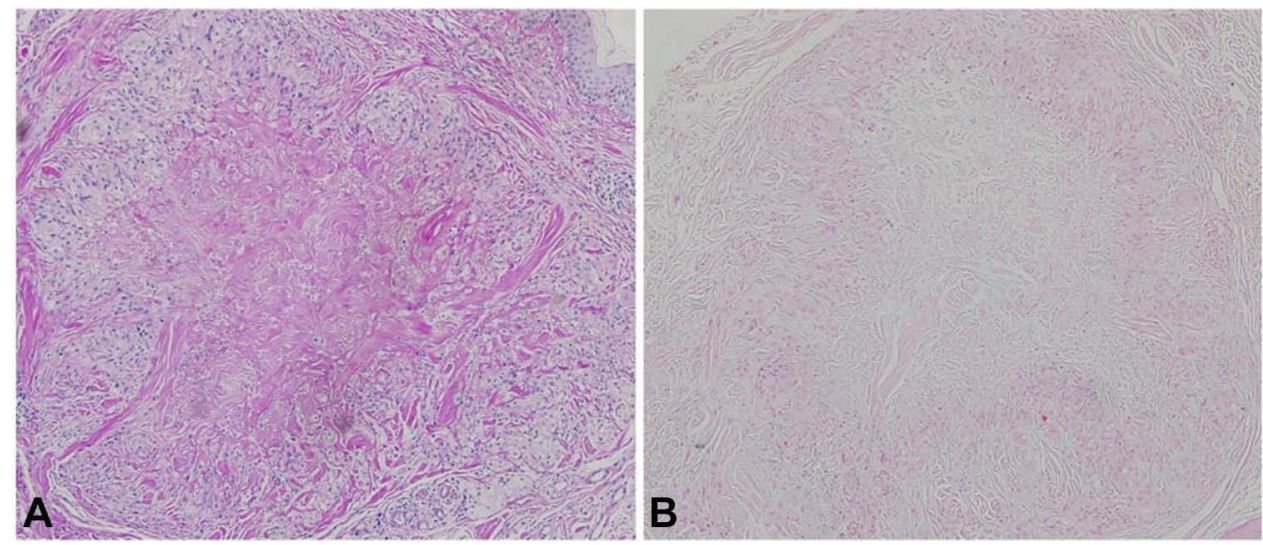

Figure 3 Immunohistochemistry of the patient. The granuloma of the patient was not immunohistochemically stained with PAS or Alcian blue, revealing no fungal infection or mucin deposition. (A PAS, $\times 100$, B Alcian blue, $\times 100$ ).

delivering these molecules through the skin have been studied. Exosomes derived from human umbilical cord blood can permeate human skin and induce collagen synthesis, resulting in skin rejuvenation. ${ }^{12}$

A granuloma is an aggregation of macrophages resulting from inflammation. Foreign body granulomas in people who have received dermal fillers simultaneously develop months after injection at all injection sites. The latent period between the time of dermal filler injection and development of the lesions that measures up to months and formation at all injection sites are reportedly clinical features that differentiate a granuloma from an early implant nodule, which develops within weeks as a single nodule. This may be explained by non-allergic chronic inflammation in granulomas triggered by dermal fillers. ${ }^{13}$ However, rare cases of granulomas appearing within weeks or even days have been reported. ${ }^{14,15}$ In this case, skin lesions appeared after several days at all injection sites, mimicking granulomas. Although a patch test with the medium was not conducted at the clinic, the short interval between the injection and the development of skin lesions suggests that the reactions may be allergic.

The histology of nodules is similar to foreign body granulomas, with dense foreign material and giant cells, which are referred to as foreign body reaction. ${ }^{16}$ Foreign body injection elicits a response through both acute and chronic inflammatory responses. In the acute phase, neutrophil recruitment and protein adsorption take place, while in the chronic phase, aggregation of monocytes and migration of fibroblasts are seen. Macrophages, differentiated from monocytes, fuse to form foreign body giant cells. Interferon gamma and tumor necrosis factor alpha play a role in the response. Matrix deposition by fibroblasts may produce a fibrous capsule. ${ }^{17}$ In granulomas, the fibrous capsule surrounding the nodules are absent. Rather, the borders of granulomas expand fingerlike into surrounding tissue. ${ }^{16}$ In this case, the border was well defined by fibrous tissues, suggesting the skin reactions at all injections sites to be foreign body reactions, alike nodules.

Although foreign body reactions are less dramatic after resorbable implants than permanent fluidal implants, formation of late foreign body granulomatous reaction had been reported in re-absorbable dermal fillers including hyaluronic acid and poly-hydroxyethyl-methacrylate suspended in hyaluronic acid. ${ }^{16,18,19}$

The injected volume, repetition of injections, impurities, particle size, particle surface, and hydrophilicity are reported to influence granulomas arising after dermal filler injections. ${ }^{13}$ Although the medium injected in the current case did not contain filler materials, it caused dermal foreign body granulomatous reactions similar to those caused by dermal fillers and therefore the aforementioned factors may have played a role. A previous report suggested that hypoxic conditions and transduction of specific genes into stem cells during the culturing process increase the levels of regenerative components in conditioned media. ${ }^{20}$ While various types and high concentrations of proteins may be beneficial in terms of regenerative potency, it may need to be confirmed that the proteins do not cause impurities to ensure safety. Purification of conditioned media may reduce the risk of granulomatous reactions.

Data are lacking about which anatomical sites are vulnerable to formation of granulomas. A previous retrospective review of patients who developed nodules after filler injections revealed that the lips were the most 
common location, followed by the nasolabial folds and cheeks. ${ }^{21}$ Regarding nodules, previously in literature, lips and periorbital areas were termed "dynamic areas" with frequent muscle movements and little subcutaneous fat, making the area not suitable for calcium hydroxylapatite filler injections. ${ }^{22} 49 \%$ of nodules were reported on the "dynamic" areas after calcium hydroxylapatite filler injection. ${ }^{22}$ The neck also shares the "dynamic" property, requiring caution in procedures within the area. A case of subcutaneous foreign body granuloma has been reported after neck dissection and adjuvant radiation. ${ }^{23}$ Procedures on the neck may require caution.

This study highlights the complication caused by dermal injection of stem cell conditioned media. The case is interesting in that clinically, the skin reactions occurred at all injection sites simultaneously mimicking granuloma, while histologically, the presence of fibrous capsule was similar to foreign body reaction of nodules.

\section{Conclusion}

Dermal injection of stem cell conditioned media may induce foreign body granulomas, the nature of which requires further investigation.

\section{Abbreviation}

PAS, periodic acid-Schiff.

\section{Ethics and Consent Statements}

The patient provided informed consent to publish their case details and any accompanying images. Institutional review board of Asan Medical Center waives institutional approval for case reports when the patient consent is attained, according to "Article 13 of the Bioethics and Safety Act", the law enacted in Korea since 2014. In this case, patient consent form was written by the patient, waiving institutional approval for publish of the case details.

\section{Disclosure}

The authors report no conflicts of interest in this work.

\section{References}

1. Won CH, Park GH, Wu X, et al. The basic mechanism of hair growth stimulation by adipose-derived stem cells and their secretory factors. Curr Stem Cell Res Ther. 2017;12(7):535-543. doi:10.2174/ 1574888X12666170829161058

2. Gunawardena TNA, Rahman MT, Abdullah BJJ, Abu Kasim NH. Conditioned media derived from mesenchymal stem cell cultures: the next generation for regenerative medicine. J Tissue Eng Regen Med. 2019;13(4):569-586. doi:10.1002/term.2806
3. Fabi S, Sundaram H. The potential of topical and injectable growth factors and cytokines for skin rejuvenation. Facial Plast Surg. 2014;30(2):157-171. doi:10.1055/s-0034-1372423

4. Lee HJ, Lee EG, Kang S, Sung JH, Chung HM, Kim DH. Efficacy of microneedling plus human stem cell conditioned medium for skin rejuvenation: a randomized, controlled, blinded split-face study. Ann Dermatol. 2014;26(5):584-591. doi:10.5021/ad.2014.26.5.584

5. Sclafani AP, McCormick SA. Induction of dermal collagenesis, angiogenesis, and adipogenesis in human skin by injection of platelet-rich fibrin matrix. Arch Facial Plast Surg. 2012;14 (2):132-136. doi:10.1001/archfaci.2011.784

6. Pawitan JA. Prospect of stem cell conditioned medium in regenerative medicine. Biomed Res Int. 2014;2014:965849. doi:10.1155/2014/ 965849

7. Park CS, Park JH, Kim CR, Lee JH. Objective analysis of volume restoration in atrophic acne scars and skin pores: a split study using human stem cell-conditioned media. J Dermatolog Treat. 2021;32 (1):73-77. doi:10.1080/09546634.2019.1628915

8. Abdel-Maguid EM, Awad SM, Hassan YS, El-Mokhtar MA, ElDeek HE, Mekkawy MM. Efficacy of stem cell-conditioned medium vs. platelet-rich plasma as an adjuvant to ablative fractional $\mathrm{CO}(2)$ laser resurfacing for atrophic post-acne scars: a split-face clinical trial. J Dermatolog Treat. 2021;32(2):242-249. doi:10.1080/ 09546634.2019.1630701

9. Kim YJ, Seo DH, Lee SH, et al. Conditioned media from human umbilical cord blood-derived mesenchymal stem cells stimulate rejuvenation function in human skin. Biochem Biophys Rep. 2018;16:96-102.

10. Fitzpatrick RE. Endogenous growth factors as cosmeceuticals. Dermatol Surg. 2005;31(7 Pt 2):827-831; discussion 831. doi:10.1111/j.1524-4725.2005.31727

11. Ono IA. Study on the alterations in skin viscoelasticity before and after an intradermal administration of growth factor. $J$ Cutan Aesthet Surg. 2011;4(2):98-104. doi:10.4103/0974-2077.85022

12. Kim YJ, Yoo SM, Park HH, et al. Exosomes derived from human umbilical cord blood mesenchymal stem cells stimulates rejuvenation of human skin. Biochem Biophys Res Commun. 2017;493 (2):1102-1108. doi:10.1016/j.bbrc.2017.09.056

13. Lee JM, Kim YJ. Foreign body granulomas after the use of dermal fillers: pathophysiology, clinical appearance, histologic features, and treatment. Arch Plast Surg. 2015;42(2):232-239. doi:10.5999/aps.2015.42.2.232

14. Bardazzi F, Ruffato A, Antonucci A, Balestri R, Tabanelli M. Cutaneous granulomatous reaction to injectable hyaluronic acid gel: another case. J Dermatolog Treat. 2007;18(1):59-62. doi:10.1080/ 09546630601121052

15. Lupton JR, Alster TS. Cutaneous hypersensitivity reaction to injectable hyaluronic acid gel. Dermatol Surg. 2000;26(2):135-137. doi:10.1046/j.1524-4725.2000.99202.x

16. Lemperle G, Gauthier-Hazan N, Wolters M, Eisemann-Klein M, Zimmermann U, Duffy DM. Foreign body granulomas after all injectable dermal fillers: part 1. Possible causes. Plast Reconstr Surg. 2009;123(6):1842-1863. doi:10.1097/PRS.0b013e31818236d7

17. Wang LL, Thomas WW, Friedman O. Granuloma formation secondary to silicone injection for soft-tissue augmentation in facial cosmetics: mechanisms and literature review. Ear Nose Throat J. 2018;97(1-2):E46-e51. doi:10.1177/0145561318097001-211

18. Signorini M, Liew S, Sundaram H, et al. Global aesthetics consensus: avoidance and management of complications from hyaluronic acid fillers-evidence- and opinion-based review and consensus recommendations. Plast Reconstr Surg. 2016;137(6):961e-971e. doi:10.1097/PRS.0000000000002184

19. Capodiferro S, Sportelli P, Limongelli L, et al. Delayed sclerosing granulomatous reaction to dermal filler injection of poly-hydroxyethyl-methacrylate suspended in hyaluronic acid: histochemical and confocal laser scanning microscopical analysis. Clin Case Rep. 2019;7(11):2215-2219. doi:10.1002/ccr3.2478 
20. Yang JA, Chung HM, Won CH, Sung JH. Potential application of adipose-derived stem cells and their secretory factors to skin: discussion from both clinical and industrial viewpoints. Expert Opin Biol Ther. 2010;10(4):495-503. doi:10.1517/14712591003610598

21. Modarressi A, Nizet C, Lombardi T. Granulomas and nongranulomatous nodules after filler injection: different complications require different treatments. J Plast Reconstr Aesthet Surg. 2020;73 (11):2010-2015. doi:10.1016/j.bjps.2020.08.012
22. Kadouch JA. Calcium hydroxylapatite: a review on safety and complications. J Cosmet Dermatol. 2017;16(2):152-161. doi: $10.1111 /$ jocd.12326

23. Mytilineos D, Hoffmann TK, Brunner C, Weißinger S, Möller P, Doescher J. Subcutaneous foreign body granuloma after neck dissection and adjuvant radiation. HNO. 2019;67(12):948-951. doi:10.1007/s00106-019-0700-0

\section{Publish your work in this journal}

The International Medical Case Reports Journal is an international, peer-reviewed open-access journal publishing original case reports from all medical specialties. Previously unpublished medical posters are also accepted relating to any area of clinical or preclinical science. Submissions should not normally exceed 2,000 words or 4 published pages including figures, diagrams and references. The manuscript management system is completely online and includes a very quick and fair peer-review system, which is all easy to use. Visit http://www.dovepress.com/testimonials.php to read real quotes from published authors. 